und Breite betrug etwa je $4 \mathrm{~cm}$, während die Dicke zwischen 5 und $10 \mathrm{~mm}$ schwankte. Nachdem ich den Gegenstand von zwei Seiten genau gezeichnet, wurde begonnen, ihn sorgfältig auseinander zu falten, und siehe da, es war eine papierdicke, lederartige Eihülle, die beim Präpariren an einer Stelle zerriss. Der stumpfe Pol ist normal, das spitze Ende dagegen in einen geknickten, fast $2 \mathrm{~cm}$ langen röhrenförmigen Hals ausgezogen, wie ich ihn schon öfter als Monstrosität bei Hühnereiern gefunden habe. Um die membranartige Haut geschmeidig zu machen, wurde sie mit Wasser angefeuchtet, sorgfältig aufgeblasen und mit Baumwolle ausgestopft. Sie hat eine regelmässige Eiform angenommen, geht an dem spitzen Ende in den genannten Fortsatz aus und ist auf ihrer Oberfläche durch die Falten, in welchen sie früher zusammengelegen hatte, in unregelmässige Vielecke getheilt. Die Entstehung dieser Eihülle wird etwa die folgende gewesen sein: das Ei war gerade in dem Stadium, in welchem es von der Kalkschale umgeben werden sollte, ist aber durch irgend welchen Zufall in die Leibeshöhle gerathen, wo es zwischen den Eingeweiden eingezwängt einem verhältnissmässig grossen Druck ausgesetzt war, so dass sein Inhalt herausgepresst und mit der Zeit vollständig resorbirt wurde. So blieb nur die consistentere Haut übrig, welche entsprechend dem Austreten des Ei-Inhaltes mehr und mehr zusammenfiel und endlich in fest gefalteter plattgedrückter Form an den Magen angepresst ward, wo sie nach dem Schlachten des Huhnes gefunden wurde. Dr. Karl Eckstein.

\title{
Turdus iliacus Linn. in Bayern nistend.
}

(Aus dem handschriftlichen Nachlass des Oberförsters C. Baumeister.)

Mittgetheilt von

0. Reiser.

In dem IX. Jahresberichte (1884) des Ausschusses für Beobachtungsstationen der Vögel Deutschlands findet sich pag. 287 zu der Notiz des im Titel genannten verewigten Oberförsters bei Turdus iliacus, welche er einmal im Jahre 1865 auf 5 Eiern brïtend am 8. Mai in den Allgäuer Alpen aufgefunden zu haben angiebt, eine Bemerkung von R. Blasius, dass diese Beobachtung so interessant ist, dass es sehr wünschenswerth wäre, ähnliche Beobachtungen aus dortiger Gegend zu erhalten. 
Leider konnte Baumeister dieser Aufforderung nicht mehr nachkommen, denn kurze Zeit darauf wurde uns dieser treffliche Beobachter durch den Tod entrissen; allein als ich am 10. Januar dieses Jahres für das bosnisch-herzegowinische Landesmuseum in Sarajevo von der Wittwe Baumeister's die prächtige Eiersammlung ihres verstorbenen Gemahls zu erwerben die Freude hatte, fand ich unter den zahlreichen Papieren und Aufzeichnungen die nachfolgenden näheren Umstände der Auffindung des Weindrosselnestes, welche es unzweifelhaft erscheinen lassen, dass es sich um ein Brutvorkommniss dieses nordischen Brutvogels in Süddeutschland wirklich handelte.

Wennschon verlässliche Fälle eines Brütens dieser Drossel in Norddeutschland selten sind und in der Regel eine solche Beobachtung auf voreiliger Annahme zu beruhen pflegt, so muss der im Folgenden vorgekommene Fall am Nordabhange der Alpen geradezu als ein Unicum bezeichnet werden.

In neuerer Zeit ist mir überhaupt nur ein Fall, der Anspruch auf Glaubwürdigkeit machen kann, aus der hübsch geschriebenen Studie von Th. Pestalozzi, das Thierleben der Landschaft Davos bekannt, wo pag. 33 eine Rothdrossel nistend beim Davoser Kulm angeführt wird.

Schon in einem Briefconcepte vom 27. November 1866 schreibt Baumeister an einen unbekannten Correspondenten, vielleicht Oberf. Hintz, von Sachsenried aus über seinen im Vorjahre gemachten glücklichen Fund Folgendes: „Ueber Turdus iliacus habe ich Euer Hochwohlgeboren zu berichten, dass im selben Sommer, als ich diese Eier in Fischen sammelte, ein männlicher oder weiblicher Vogel (von 2 Stücken) bei Wollmetshofen im Juni geschossen wurden. Ueberdies hat mein Vater selig mir oft gesagt, dass ich T. iliacus nistend bei uns finden könne, da er Vögel im Sommer angetroffen - dies zur Notiz und als weiterer Beweis für das Brïten des Turdus iliacus in siidlichen Gegenden."

Offenbar auf die Anmerkung in dem Beobachtungsstationsbericht hin hat Baumeister kurz vor seinem Tode ausführlicher seinen Fund vom Jahre 1865 beschrieben. Auf einem Forst-, Jagdund Trift-Rechnungs-Bogen findet sich unter dem in der Ueberschrift beibehaltenen Titel:

„Die Wein- oder Rothdrossel ist bekanntlich ein Vogel des Nordens, brütet auf Island, in Norwegen, Lappland, Insel Tromsoë, Archangelsk, Gouvernement Curland, Gottland, Krotoschin, Esthland, 
182 Dr. A. Köni g: Vorläufige Notiz über zwei neue Vogelarten.

Polen, Russland und Finnland in Birkenwäldern und Erlen-Brüchern. Dass sie aber auch in Süddeutschland niste, wurde noch nicht erwiesen; ich kann jedoch einen Fall constatiren, wo sie bei uns und zwar bei Fischen im Allgäu genistet hat.

Es war am 8. Mai 1865, als ich in den sogenannten Illerauen gelegentlich der dort stattfindenden Forstcultur ein äusserlich aus gröberen, innerlich mit feineren Halmen gebautes, von den Nestern anderer bei uns vorkommenden Drosselarten wohl unterscheidbares Nest in einem Erlen- und Fichtenstrauche $2^{4}$ von der Erde entfernt mit 5 frisch gelegten Eiern entdeckte.

Ich wollte den Vogel erlegen, jedoch liess mich derselbe auf Schussnähe nicht ankommen. Derselbe war sehr scheu, gab nur ein paar kurze Laute von sich, und so musste ich auf denselben verzichten, welcher von mir genau als Turdus iliacus erkannt wurde, befürchtend, es könnte mir das Nest sammt seinem Inhalte entgehen.

Der Standort des Nestes lag in einem Gebirgsthale ca. 3000' über der Meeresfläche am Fusse des Stubingerhorn und hatte daher offenbar viel Aehnlichkeit mit dem eigentlichen Brutstandort im Norden, so dass dieser einzelne Fall leicht erklärt werden kann, um so mehr, als schon einzelne Weindrosseln im Frühjahre und zwar noch im Monate Mai in der Nähe von Augsburg vor Kurzem beobachtet worden sind. Die Eier waren länglich in ihrer Form, kleiner als diejenigen der Merula vulgaris, von blaugrünlicher lebhafter Grundfarbe, welche die sonst vorkommenden, mehr oder weniger rostbrannen kleinen Flecken kaum erkennen lässt, ohne schwarze Punkte. Die ziemlich glänzende, glatte Schale ist am ähnlichsten den Eiern von Merula und T. pilaris. Der Charakter der Zeichnung gehört zum Färbungstypus von Merula. Maasse: 22-25 mm lang, $17-18 \mathrm{~mm}$ breit."

Gegenwärtig befindet sich dieses Gelege sammt der übrigen Sammlung Baumeister's im bosnisch-herzegowinischen Landesmuseum in Sarajevo und es ist nach Obigem wohl nicht zu bezweifeln, dass hier ein authentischer, wenngleich vereinzelter Fall des Brïtens der Weindrossel in den suiddeutschen bayrischen Alpen vorliegt.

\section{Vorläufige Notiz}

\section{ïber zwoi neue Vogelarten von den Canarischen Inseln.} Von

\section{Dr. A. König, in Bonn.}

Auf meiner im vergangenen Winter unternommenen Reise nach den Canarischen Inseln erbeutete ich unter einem umfangreichen Material der dortigen Ornis zwei gute bisher noch unbekannte Vogelarten, welche ich vorläufig bekannt zu machen wünsche und die kurze Beschreibung wie folgt gebe. Die ge- 


\section{$2 \mathrm{BHL}$ Biodiversity Heritage Library}

1889. "Turdus iliacus Linn. in Bayern nistend." Journal fu

r Ornithologie 37, 180-182. https://doi.org/10.1007/bf02252483.

View This Item Online: https://www.biodiversitylibrary.org/item/102840

DOI: https://doi.org/10.1007/bf02252483

Permalink: https://www.biodiversitylibrary.org/partpdf/142483

\section{Holding Institution}

Smithsonian Libraries

\section{Sponsored by}

Biodiversity Heritage Library

\section{Copyright \& Reuse}

Copyright Status: Public domain. The BHL considers that this work is no longer under copyright protection.

This document was created from content at the Biodiversity Heritage Library, the world's largest open access digital library for biodiversity literature and archives. Visit BHL at https://www.biodiversitylibrary.org. 